\title{
Does surgical delay for radical prostatectomy affect patient pathological outcome? A retrospective analysis from a Canadian cohort
}

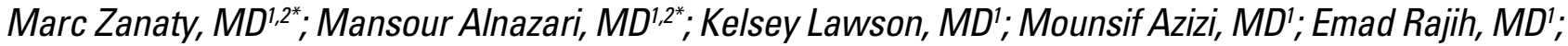 \\ Abdullah Alenizi, MD'; Pierre-Alain Hueber, MD'; Malek Meskawi, MD'; Cedric Lebacle, MD³; Thierry Lebeau, MD2; \\ Serge Benayoun, MD'; Pierre I. Karakiewicz, MD'; Assaad El-Hakim, MD',2; Kevin C. Zorn, MD',2
}

*Both authors participated equally to the study and are considered equal first authors.

'Division of Urology, Department of Surgery, Centre Hospitalier Universitaire de Montréal (CHUM), Montreal, QC, Canada; ${ }^{2}$ Division of Robotic Urology, Department of Surgery, Hôpital du Sacré Coeur de Montréal, Montreal, QC, Canada; ${ }^{3}$ Department of Urology, CHU Mondor, Assistance Publique des Hôpitaux de Paris, Université Paris-Est, Créteil, France

Cite as: Can Urol Assoc J 2017;11 (8):265-9. http://dx.doi.org/10.5489/cuaj.4149

\section{Abstract}

Introduction: We sought to assess the impact of surgical wait time (SWT) to robot-assisted radical prostatectomy (RARP) on final pathological outcome.

Methods: A retrospective review of RARP patient records operated between 2006 and 2015 was conducted. SWT was defined as period from prostate biopsy to surgery. Primary outcome was the impact on postoperative Cancer of the Prostate Risk Assessment (CAPRA-S) score. Patients were stratified according to D'Amico risk categories. Univariate analysis (UVA) and multivariable (MVA) analysis with a generalized linear model was used to evaluate the effect of SWT and other predictive factors on pathological outcome in individual risk group and on the overall sample.

Results: A total of 835 patients were eligible for analysis. Mean SWT was significantly different between the three D'Amico groups, with mean SWT of 180.22 days (95\% confidence interval [CI] 169.03; $191.41), 159.14$ days $(95 \% \mathrm{Cl} 152.38 ; 165.90)$, and 138.96 days (95\% Cl 124.60; 153.33) for low-, intermediate-, and high-risk groups, respectively $(p<0.001)$. After stratification by D'Amico risk group, no significant association was observed between SWT and CAPRA-S score in the three risk categories on UVA and MVA. Predictors of higher CAPRA-S score in the multivariable model in the overall cohort were: older age $(p=0.014)$, biopsy Gleason score $(p<0.001)$, percentage of positive cores $(p<0.001)$, and clinical stage $(p<0.001)$.

Conclusions: In the present study evaluating SWT for RARP in a Canadian socialized system, increased delay for surgery does not appear to impact the pathological outcome. Further studies are required to evaluate the impact of wait time on biochemical recurrence-free survival, cancer-specific survival, and overall survival.

\section{Introduction}

Prolonged surgical wait time (SWT) have an impact on the overall quality of life and patient anxiety. Extending the wait time beyond a given threshold can also have a negative impact on the patient's clinical outcomes. Indeed, it has been established for non-urological cancer types that prolonged wait time has negative impact on oncological outcomes. ${ }^{1-4}$

With SWT on the rise in Canada, ${ }^{5}$ it is important to question its impact on prostate cancer pathological outcomes, particularly for men awaiting robot-assisted radical prostatectomy (RARP) due to limited access to such technology. ${ }^{6,7}$ In the era predating robotic surgery in Canada, a systematic review of the literature by Saad et al in 2006 reported that the median wait time for prostatectomy varied from 42 days (consultation to operation) to 83 days (consultation to hospital admission). ${ }^{8}$ Furthermore, their review demonstrated that Canada, unlike other comparable industrialized countries, seemed to have a steadily increasing wait time. ${ }^{8}$ Concerns that prolonged wait time may negatively influence patients' oncological outcomes arise. Furthermore, very few studies have reported a trend toward increased risk of biochemical recurrence (BCR)-associated with surgical delays for prostate cancer. ${ }^{9-11}$ Therefore, the true impact of surgical delay remains controversial and the acceptable wait time is currently unknown. As such, we sought to address the impact of SWT to RARP on pathological outcomes for patients in two major academic centres in Canada. 


\section{Methods}

\section{Patient characteristics}

After ethical review board approval, a prospectively collected robotic radical prostatectomy database from two major centres in Montreal (Hôpital du Sacré Couur de Montréal and Hôpital Saint Luc) was queried to identify all patients who underwent RARP between 2006 and 2015. All cases were performed by one of two fellowship trained, experienced robotic surgeons $(\mathrm{AEH}, \mathrm{KCZ})$ using the previously reported technique. ${ }^{12-14} \mathrm{~A}$ total of 835 patients had complete demographic, clinical, and pathologic data.

\section{SWT evaluation}

Time to surgery was calculated based on the difference between the date of diagnostic transrectal ultrasound (TRUS) biopsy and the date of surgery. Time from biopsy to robotic surgery consultation (date of RARP booking request) and from booking to actual surgery were also calculated for the overall cohort and in each D'Amico risk group. ${ }^{15}$ Adverse pathological outcome was measured by the Cancer of the Prostate Risk Assessment (CAPRA-S) score, which has been well-documented to correlate with BCR, and cancer specific survival (CSS). ${ }^{16-22}$ CAPRA-S score includes initial PSA, pathological Gleason, extracapsular extension (ECE), surgical margins (SM) status, seminal vesicle invasion (SVI), and lymph node (LN) status if lymph node dissection was done. Patients, who did not have LN dissection were considered LN-negative to calculate CAPRA-S score.

\section{Statistical analysis}

In order to test the association between predictive variables and CAPRA-S score, univariate analysis (UVA) and multivariable analysis (MVA) were done using a generalized linear model. SWT was considered a continuous variable. All statistical tests were two-sided with a level of significance set at $p<0.05$. Analyses were performed using the $R$ software environment for statistical computing and graphics (version 3.3.3; http://www.r-project.org/).

\section{Results}

Baseline characteristics are displayed in Table 1.

SWT was significantly different among the three D'Amico risk groups, with mean SWT of 180.22 days (95\% confidence interval $[\mathrm{Cl}] 169.03 ; 191.41), 159.14$ days $(95 \% \mathrm{Cl}$ $152.38 ; 165.90)$, and 138.96 days $(95 \% \mathrm{Cl} 124.60 ; 153.33)$ for low-, intermediate-, and high-risk groups, respectively $(p<0.001)$. To control for this bias, a subgroup analysis was carried out on three groups: low-, intermediate-, and high-
Table 1. Baseline characteristics of the overall cohort

\begin{tabular}{|c|c|c|c|}
\hline & Low-risk & $\begin{array}{l}\text { Intermediate- } \\
\text { risk }\end{array}$ & High-risk \\
\hline $\begin{array}{l}\text { Mean age, years } \\
(95 \% \mathrm{Cl})\end{array}$ & $\begin{array}{c}58.62 \\
(57.78,59.46)\end{array}$ & $\begin{array}{c}61.18 \\
(60.65,61.72)\end{array}$ & $\begin{array}{c}63.71 \\
(62.49,64.93)\end{array}$ \\
\hline $\begin{array}{l}\text { Mean PSA, ng/ml } \\
(95 \% \mathrm{Cl})\end{array}$ & $\begin{array}{c}5.09 \\
(4.85,5.33)\end{array}$ & $\begin{array}{c}6.47 \\
(6.20,6.74)\end{array}$ & $\begin{array}{c}11.14 \\
(9.14,13.13)\end{array}$ \\
\hline $\begin{array}{l}\text { Mean biopsy } \\
\text { Gleason score }\end{array}$ & 6 & 6.93 & 7.93 \\
\hline Gleason score, $\mathrm{n}(\%)$ & $240(100)$ & & \\
\hline 6 & & $30(6.07)$ & $4(4.04)$ \\
\hline $3+4$ & & 364 (73.68) & $10(10.10)$ \\
\hline $4+3$ & & $100(20.24)$ & 7 (7.07) \\
\hline $8-10$ & & & $78(78.78)$ \\
\hline \multicolumn{4}{|l|}{ Clinical stage, $\mathrm{n}(\%)$} \\
\hline cT1b & & & $1(1.01)$ \\
\hline cT1c & $205(85.41)$ & $356(72.06)$ & $45(45.45)$ \\
\hline ст2a & $35(14.58)$ & $110(22.26)$ & $24(24.24)$ \\
\hline cT2b & & $28(5.66)$ & $14(14.14)$ \\
\hline cT2c & & & $10(10.10)$ \\
\hline cT3 & & & $5(5.05)$ \\
\hline $\begin{array}{l}\text { Mean TRUS } \\
\text { prostate volume } \\
(95 \% \mathrm{Cl})\end{array}$ & $\begin{array}{c}31.58 \\
(30.99,32.18)\end{array}$ & $\begin{array}{c}31.60 \\
(31.11,32.08)\end{array}$ & $\begin{array}{c}31.74 \\
(30.69,32.78)\end{array}$ \\
\hline Mean BMI $(95 \% \mathrm{Cl})$ & $\begin{array}{c}38.93 \\
(36.91,40.96)\end{array}$ & $\begin{array}{c}39.83 \\
(38.32,41.34)\end{array}$ & $\begin{array}{c}41.45 \\
(37.74,45.16)\end{array}$ \\
\hline
\end{tabular}

risk. Wait time from biopsy to booking, as well as from booking to surgery in the overall cohort and for each D'Amico risk group are presented in Table 2 .

Upon analyzing the entire study cohort with MVA, advanced age $(p=0.014)$, higher biopsy Gleason score $(p<0.001)$, advanced clinical stage $(<0.001)$ and higher percentage of positive cores $(<0.001)$, were predictors of pathological post-surgical CAPRA-S score; however, SWT did not affect CAPRA-S score $(p=0.196)$ (Table 3).

\begin{tabular}{|c|c|c|c|}
\hline & $\begin{array}{c}\text { Mean days } \\
\text { between } \\
\text { prostate } \\
\text { biopsy to } \\
\text { surgical } \\
\text { booking }\end{array}$ & $\begin{array}{l}\text { Mean days } \\
\text { between } \\
\text { surgical } \\
\text { booking to } \\
\text { surgery }\end{array}$ & $\mathbf{p}$ \\
\hline Overall SWT (95\% CI) & $\begin{array}{c}87.10(81.39 \\
92.82)\end{array}$ & $\begin{array}{c}76.59(72.72 \\
80.47)\end{array}$ & 0.002 \\
\hline High-risk (95\% Cl) & $\begin{array}{c}81.44(65.52, \\
97.35)\end{array}$ & $\begin{array}{c}55.21(44.12 \\
66.30)\end{array}$ & 0.008 \\
\hline $\begin{array}{l}\text { Intermediate-risk } \\
(95 \% \mathrm{Cl})\end{array}$ & $\begin{array}{c}82.79(76.57 \\
89.00)\end{array}$ & $\begin{array}{c}76.76(72.02 \\
81.49)\end{array}$ & 0.120 \\
\hline Low-risk (95\% Cl) & $\begin{array}{c}97.22(84.17 \\
110.27)\end{array}$ & $\begin{array}{c}86.38(78.52 \\
94.24)\end{array}$ & 0.161 \\
\hline $\mathrm{p}$ & 0.063 & $<0.001$ & \\
\hline
\end{tabular}




\begin{tabular}{|c|c|c|c|c|}
\hline & OR & Cl lower & Cl upper & $\mathbf{p}$ \\
\hline SWT & 1.001 & 0.999 & 1.003 & 0.196 \\
\hline Biopsy Gleason score & 3.400 & 2.747 & 4.207 & $<0.001$ \\
\hline Positive cores percentage & 1.014 & 1.006 & 1.021 & $<0.001$ \\
\hline Clinical stage & 2.987 & 1.888 & 4.726 & $<0.001$ \\
\hline Age & 1.027 & 1.005 & 1.050 & 0.014 \\
\hline $\mathrm{BMI}$ & 1.015 & 0.989 & 1.042 & 0.268 \\
\hline TRUS prostate volume & 0.998 & 0.990 & 1.007 & 0.694 \\
\hline
\end{tabular}

BMl: body mass index; Cl: confidence interval; OR: odds ratio; SWT: surgical wait time;

TRUS: transrectal ultrasound.

On subgroup analysis, there was no association between SWT and CAPRA-S on UVA and MVA for low-, intermediate-, and high-risk groups.

\section{Discussion}

This study provides unique insight on prolonged SWT caused by limited resources and operative time associated with public healthcare in Canada, as well as its impact on pathological outcomes. SWT for RARP is long and seems to be longer than previously reported for open radical prostatectomy (ORP) in 2006 by Saad et al; ${ }^{8}$ however, further increase in SWT appear to have no impact on pathological outcomes, as represented by CAPRA-S score in the present study.

Similar to previously reported studies on surgical delay, our SWT was defined as the interval of time between biopsy date and surgical intervention. ${ }^{10,23-26}$ Furthermore, the overall SWT was divided into time from biopsy to booking of surgery (overall mean of 87.1 days) and time from booking to surgery (overall mean of 76.6 days). To the best of our knowledge, this is the first unique reporting of SWT categorization. Both time intervals observed are long compared to most other U.S. and European centres, which reflects not only the delay in operating room scheduling and access to surgical time, but in the other steps of patient management as well. More specifically, in our universal Canadian system, particularly in the province of Quebec, the typical time from biopsy to pathology report finalization is $3-4$ weeks. For high-risk patients, the turnaround time to schedule a nuclear medicine bone scan and computed tomography (CT) scan is approximately 30 days, and additional delay is added to do the interpretation of the imaging studies, followed by the interval of time during which the exam transcription will be sent to the urologist. This is based on our clinical experience. Also of note, the majority of men treated by RARP were initially worked up by a community urologist and then referred for RARP surgery. As such, the pre-booking wait time was consistent among all three groups, as this period is out of the operating surgeon's influence. With regards to the time from surgery booking to the procedure, we observed a significant difference between the subgroups (Table 2). Men with higher-risk disease had RARP done quicker, suggesting the influence of the surgeon/scheduling team who are consciously expediting surgery. As expected, SWT was longer for lower D'Amico risk groups.

It is important to highlight that many of the previously published studies on SWT were based on low-risk prostate cancer patients who were on active surveillance (AS). ${ }^{11,26-29}$ Understandably, this is one of a few ways to ethically study SWT with prolonged delays. Otherwise, in most other global centres, men who are not eligible for AS are operated with minimal delay, considering greater access to surgical resources. Due to the prolonged SWT in Canada, particularly in a country with only 25 Da Vinci robot systems for a population of 36.2 million, ${ }^{30}$ we had the unique opportunity to evaluate the effect of delay for patients with intermediate- and high-risk disease.

Several studies have previously observed negative associations between prolonged SWT and adverse outcomes $^{24,25,27,29,31,32}$ or have demonstrated positive association only on UVA that became negative on MVA after adjustment. ${ }^{33,34}$ The majority of such reports were conducted on low-risk patients. ${ }^{10,31,35-38}$ Despite relatively long SWT in our cohort, there was no observed effect on CAPRA-S scores in the low-risk group, suggesting that surgery can be performed safely within six months of biopsy. This seems intuitive to a low-risk group where AS may be a treatment option.

In the intermediate-risk subgroup of Holmstrom et al, upgrading of Gleason score was higher for patients who had deferred prostatectomy (median wait time was 3.5 months for primary and 19.2 months for deferred group). No difference in overall mortality was observed at eight years followup. ${ }^{28}$ Furthermore, Abern et al demonstrated that delay over nine months (biopsy to surgery) was associated with greater positive surgical margin (PSM) $(p=0.005)$ for the intermediate-risk group on multivariate analysis. ${ }^{10}$ PSMs were, $47 \%$, $50 \%, 50 \%$, and $76 \%$, for delays $<3$ months, 3-6 months, 6-9 months and $>9$ months, respectively. Similarly, Berg et al determined a cutoff of 60 days for adverse pathological outcomes for patients with Gleason 7 and prostate-specific antigen $(P S A)>20(p=0.032) .{ }^{23}$ The above mentioned studies showed positive association between wait time and pathological features used separately. Our study showed negative association of SWT with overall adverse pathological features represented by CAPRA-S score. To the best of our knowledge, this represents the first study to use the CAPRA-S as an outcome measure.

For high-risk prostate cancer, only a couple have identified association between SWT and oncological outcomes ${ }^{9,23}$ - albeit few studies were conducted. No association was found in our subgroup analysis for high-risk patients.

In contrast with other studies on adverse pathological outcomes, where several pathological features were consid- 
ered endpoints, ${ }^{23,27,28}$ we used a unique primary objective endpoint, namely the CAPRA-S score, which combines all relevant pathological features and has proved to be a strong postoperative predictor of prostate cancer oncological outcomes. ${ }^{39-41}$ Also, the universal healthcare context with limited access to resources make this study unique, allowing the inclusion of a good number of intermediate- and high risk patients.

Limitations of our study include its retrospective nature, which is subject to biases inherent to retrospective studies. The main outcome was the pathological features represented by a validated composed score, CAPRA-S score (which is a well-recognized surrogate for BCR), cancer-specific survival, and overall survival. Additionally, we must take into account the effect of local policies in two respective hospitals and urologists applying individualized wait times for every case. We tried to compensate for this selection bias by stratifying our patients with the D'Amico risk groups and adjusting in MVA.

\section{Conclusion}

In the present study, we evaluated SWT for Canadian men in a publicly funded, universal healthcare system and evaluated variation between $\mathrm{D}^{\prime}$ Amico risk categories and impact on CAPRA-S post-surgical scores. Based on our findings, it appears that SWT does not affect pathological outcome. While surgeon case selection appears to influence SWT, other factors also require closer evaluation to improve timing to definitive prostate cancer treatment. Further studies are warranted to assess the impact of SWT on BCR-free survival, cancer-specific survival, and overall survival.

Competing interests: The authors report no competing personal or financial interests.

This paper has been peer-reviewed.

\section{References}

1. Huang J, Barbera $\mathrm{L}$, Brouwers $\mathrm{M}$, et al. Does delay in starting treatment affect the outcomes of radiotherapy? A systematic review. J Clin Oncol 2003;21:555-63. https://doi.org/10.1200/JC0.2003.04.171

2. $0^{\prime}$ Rourke N, Edwards R. Lung cancer treatment waiting times and tumour growth. Clin Oncol 2000;12:1414. https://doi.org/10.1053/don.2000.9139

3. Kulkarni GS, Urbach DR, Austin PC, et al. Longer wait times increase overall mortality in patients with bladder cancer. J Urol 2009;182:1318-24. https://doi.org/10.1016/i.juro.2009.06.041

4. Bourgade V, Drouin SJ, Yates DR, et al. Impact of the length of time between diagnosis and surgical removal of urologic neoplasms on survival. World J Urol 2014;32:475-9. https://doi.org/10.1007/ s00345-013-1045-z

5. Siemens DR, Schulze KM, Mackillop WJ, et al. A population-based study of the waiting times for prostatectomy in Ontario. Can J Urol 2005;12:2568-74.

6. Maurice MJ, Zhu H, Kim SP, et al. Robotic prostatectomy is associated with increased patient travel and treatment delay. Can Urol Assoc J 2016;10:192-201. https://doi.org/10.5489/cuai.3628

7. Zorn KC, Zanaty M, El-Hakim A. Robotic prostatectomy and access to care: Canadian vs. U.S. experience. Can Urol Assoc J 2016;10:202-3. https://doi.org/10.5489/cuaj.3846
8. Saad $F$, Finelli $A$, Dranitsaris $G$, et al. Does prolonging the time to prostate cancer surgery impact long-term cancer control: A systematic review of the literature. Can J Urol 2006;13Suppl3:16-24.

9. Nguyen PL, Whittington R, Koo S, et al. The impact of a delay in initiating radiation therapy on prostatespecific antigen outcome for patients with clinically localized prostate carcinoma. Cancer 2005; 103:20539. https://doi.org/10.1002/cncr.21050

10. Abern MR, Aronson WJ, Terris MK, et al. Delayed radical prostatectomy for intermediate-risk prostate cancer is associated with biochemical recurrence: Possible implications for active surveillance from the SEARCH database. The Prostate 2013;73:409-17. https://doi.org/10.1002/pros.22582

11. O'Brien D, Loeb $S$, Carvalhal GF, et al. Delay of surgery in men with low-risk prostate cancer. J Urol 2011;185:2143-7. https://doi.org/10.1016/i.juro.2011.02.009

12. Valdivieso RF, Hueber P-A, Zorn KC. Robot-assisted radical prostatectomy: How I do it. Part I: Patient preparation and positioning. Can J Urol 2013;20:6957-61

13. Valdivieso RF, Hueber P-A, Zorn KC. Robot-assisted radical prostatectomy: How I do it. Part II: Surgical technique. Can J Urol 2013;20:7073-8.

14. Al-Hathal N, E-Hakim A. Perioperative, oncological and functional outcomes of the first robotic prostatectomy program in Quebec: Single fellowship-trained surgeon's experience of 250 cases. Can Urol Assoc $J$ 2013;7:326-32. https://doi.org/10.5489/cuaj.319

15. D'Amico AV, Whittington R, Malkowicz SB, et al. Biochemical outcome after radical prostatectomy, external beam radiation therapy, or interstitial radiation therapy for clinically localized prostate cancer. JAMA 1998;280:969-74. https://doi.org/10.1001/jama.280.11.969

16. Aktas BK, Ozden C, Bulut $S$, et al. Evaluation of biochemical recurrence-free survival after radical prostatectomy by cancer of the prostate risk assessment post-surgical (CAPRA-S) score. Asian Pac J Cancer Prev 2015;16:2527-30. https://doi.org/10.7314/APJCP.2015.16.6.2527

17. Cooperberg MR, Hilton JF, Carroll PR. The CAPRA-S score: A straightforward tool for improved prediction of outcomes after radical prostatectomy. Cancer 2011;117:5039-46. https://doi.org/10.1002/ cncr. 26169

18. Dahm P. ACP Journal Club. The six-item CAPRA-S score predicted cancer recurrence after radical prostatectomy. Ann Intern Med 2013;159:JC13. https://doi.org/10.7326/0003-4819-159-10-20131119002013

19. Punnen S, Freedland SJ, Presti JC, et al. Multi-institutional validation of the CAPRA-S score to predict disease recurrence and mortality after radical prostatectomy. Eur Urol 2014;65:1171-7. https://doi.org/10.1016/i.eururo.2013.03.058

20. Seo WI, Kang PM, Kang DI, et al. Cancer of the Prostate Risk Assessment (CAPRA) preoperative score vs. postoperative score (CAPRA-S): Ability to predict cancer progression and decision-making regarding adjuvant therapy after radical prostatectomy. J Korean Med Sci 2014;29:1212-6. https://doi.org/10.3346/ jkms.2014.29.9.1212

21. Tiki D, Mandel P, Schlomm T, et al. External validation of the CAPRA-S score to predict biochemical recurrence, metastasis, and mortality after radical prostatectomy in a European cohort. J Urol 2015;193:19705. https://doi.org/10.1016/i.juro.2014.12.020

22. Zimmermann $M$, Delouya $G$, Alenizi AM, et al. CAPRA-S predicts outcome for adjuvant and salvage external beam radiotherapy after radical prostatectomy. Can Urol Assoc J 2016;10:132-6. htrps://doi.org/10.5489/cuai.3365

23. Berg WT, Danzig MR, Pak JS, et al. Delay from biopsy to radical prostatectomy influences the rate of adverse pathologic outcomes. The Prostate 2015;75:1085-91. https://doi.org/10.1002/pros.22992

24. Korets $R$, Seager $C M$, Pitman $M S$, et al. Effect of delaying surgery on radical prostatectomy outcomes: $A$ contemporary analysis. BJU Int 2012;110:211-6. https://doi.org/10.1111/i.1464-410X.2011.10666.x

25. Vickers AJ, Bianco $\mathrm{FJ}$, Boorijan $\mathrm{S}$, et al. Does a delay between diagnosis and radical prostatectomy increase the risk of disease recurrence? Cancer 2006;106:576-80. https://doi.org/10.1002/cncr.21643

26. Sun $M$, Abdollah $F$, Hansen J, et al. Is a treatment delay in radical prostatectomy safe in individuals with low-risk prostate cancer? J Sex Med 2012;9:2961-9. https://doi.org/10.1111/i.17436109.2012.02806.x

27. Dall'Era MA, Cowan JE, Simko J, et al. Surgical management after active surveillance for low-risk prostate cancer: Pathological outcomes compared with men undergoing immediate treatment. BJU Int 2011;107:1232-7. https://doi.org/10.1111/i.1464-410X.2010.09589.x

28. Holmström B, Holmberg E, Egevad L, et al. Outcome of primary vs. deferred radical prostatectomy in the National Prostate Cancer Register of Sweden Follow-Up Study. J Urol 2010;184:1322-7. htrps://doi.org/10.1016/i.juro.2010.06.008

29. Van den Bergh RCN, Steyerberg EW, Khatami A, et al. Is delayed radical prostatectomy in men with low-risk screen-detected prostate cancer associated with a higher risk of unfavourable outcomes? Cancer 2010;116:1281-90. https://doi.org/10.1002/cncr.24882

30. Canada Population (2016). Worldometers [cited 2016 Aug 3]. Available at http://www.worldometers. info/world-population/canada-population/. Accessed June 30, 2017. 


\section{${ }^{9} \mathrm{XGEVA}$ (denosumab)}

Indication and clinical use:

- XGEVA is indicated for reducing the risk of developing skeletal-related events (SREs) in patients with bone metastases from breast cancer, prostate cancer, non-small cell lung cancer, and other solid tumours.

- Not indicated for reducing the risk of developing skeletal-related events in patients with multiple myeloma.

- Not indicated for reducing the risk of developing skeletal-related events in pediatric patients.

\section{Contraindication:}

-XGEVA is contraindicated in patients with pre-existing hypocalcemia, which must be corrected prior to initiating therapy.

\section{Most serious warnings and precautions:}

Osteonecrosis of the jaw (ONJ): In clinical trials, the incidence of ONJ was higher with longer duration of exposure. In patients with risk factors for ONJ, an individual risk/benefit assessment should be performed before initiating therapy with XGEVA. An oral exam should be performed and a dental exam with appropriate preventive dentistry is recommended prior to treatment with XGEVA, especially in patients with risk factors for ONJ. Avoid invasive dental procedures while receiving XGEVA. In patients who develop ONJ during treatment with XGEVA, a temporary interruption of treatment should be considered based on individual risk/benefit assessment until the condition resolves.

\section{other relevant warnings and precautions:}

-Do not use concurrently with Prolia

-Do not use concurrently with bisphosphonates

- Hypocalcemia has been reported (including severe symptomatic hypocalcemia and fatal cases). Monitor calcium prior to the initial dose, within two weeks after the initial dose, and if suspected symptoms of hypocalcemia occur. Administer adequate calcium, vitamin $\mathrm{D}$, and magnesium, as necessary. If hypocalcemia occurs while receiving XGEVA, additional short-term calcium supplementation and additional monitoring may be necessary.

- Caution on risk of hypocalcemia and accompanying increases in parathyroid hormone in patients with renal impairment

- Clinically significant hypercalcemia has been reported in XGEVA-treated patients with growing skeletons weeks to months following treatment discontinuation. Monitor patients for signs and symptoms of hypercalcemia and treat appropriately.

- Skin infections

- Hypersensitivity reactions including anaphylaxis

- Atypical femoral fractures

- Not recommended for use in pregnant women. Women should not become pregnant during treatment and for at least 5 months after the last dose of XGEVA.

- For nursing women, it is not known whether XGEVA is excreted into human milk.

\section{For more information:}

Please consult the Product Monograph at

http://www.amgen.ca/Xgeva PM.pdf for important information relating to adverse reactions, drug interactions, and dosing that have not been discussed here.

The Product Monograph is also available by calling Amgen Medical Information at 1-866-502-6436.

\section{Fizazi et al. study ${ }^{2}$}

Phase 3, randomized, double-blind, double-dummy, active-controlled study. Patients with castrate-resistant prostate cancer and bone metastases $(n=1901)$ received either $120 \mathrm{mg} \mathrm{XGEVA}{ }^{\otimes}$ SC Q4W (once every 4 weeks) ( $\mathrm{n}=950$ ) or $4 \mathrm{mg}$ zoledronic acid IV Q4W $(\mathrm{n}=951)$. The primary outcome measure was to demonstrate non-inferiority of time to first on-study SRE as compared to zoledronic acid. The secondary outcome measures were superiority of time to first on-study SRE and superiority of time to first and subsequent SREs. An SRE is defined as any of the following: pathologic fracture, radiation therapy to bone, surgery to bone or spinal cord compression.

References:

1. XGEVA ${ }^{\circledR}$ Product Monograph, Amgen Canada, 2016.

2. Fizazi K, et al. Denosumab versus zoledronic acid for treatment of bone metastases in men with castration-resistant prostate cancer: a randomized, double-blind study. Lancet. 2011;377(9768):813-822.
31. Lee DK, Allareddy V, O'donnell MA, et al. Does the interval between prostate biopsy and radical prostatectomy affect the immediate postoperative outcome? BJU Int 2006;97:48-50. https://doi.org/10.1111/i.1464-410X.2006.05861.x

32. Phillips JJ, Hall MC, Lee WR, et al. Does a delay in initiating definitive therapy affect biochemical recurrence rates in men with clinically localized prostate cancer? Urol Oncol 2007;25:196-200. https://doi.org/10.1016/i.urolonc.2006.06.004

33. Van den Bergh RCN, Albertsen $\mathrm{PC}$, Bangma $\mathrm{CH}$, et al. Timing of curative treatment for prostate cancer: A systematic review. Eur Urol 2013;64:204-15. https://doi.org/10.1016/i.eururo.2013.02.024

34. Nam RK, Jewett MAS, Krahn MD, et al. Delay in surgical therapy for clinically localized prostate cancer and biochemical recurrence after radical prostatectomy. Can J Urol 2003;10:1891-8.

35. Khan MA, Mangold LA, Epstein JI, et al. Impact of surgical delay on long-term cancer control for clinically localized prostate cancer. J Urol 2004;172:1835-9. https://doi.org/10.1097/01. ju.0000140277.08623.13

36. Graefen M, Walz J, Chun K-HF, et al. Reasonable delay of surgical treatment in men with localized prostate cancer — impact on prognosis? Eur Urol 2005;47:756-60. https://doi.org/10.1016/i. eururo.2005.02.004

37. Boorijan SA, Bianco FJ, Scardino PT, et al. Does the time from biopsy to surgery affect biochemical recurrence after radical prostatectomy? BJU Int 2005;96:773-6. https://doi.org/10.1111/j.1464410X.2005.05763.x

38. Freedland SJ, Kane CJ, Amling CL, et al. Delay of radical prostatectomy and risk of biochemical progression in men with low-isk prostate cancer. J Urol 2006;175:1298-302; discussion 1302-3. https://doi.org/10.1016/S0022-5347(05)00646-4

39. Cooperberg MR, Hilton JF, Carroll PR. The CAPRA-S score: A straightforward tool for improved prediction of outcomes after radical prostatectomy. Cancer 2011;117:5039-46. https://doi.org/10.1002/ cncr.26169

40. Punnen S, Freedland SJ, Presti JC, et al. Multi-institutional validation of the CAPRA-S score to predict disease recurrence and mortality after radical prostatectomy. Eur Urol 2014;65:1171-7. https://doi.org/10.1016/i.eururo.2013.03.058

41. Tilki D, Mandel P, Schlomm T, et al. External validation of the CAPRA-S score to predict biochemical recurrence, metastasis and mortality after radical prostatectomy in a European cohort. J Urol 2015;193:1970-5. https://doi.org/10.1016/i.juro.2014.12.020

Correspondence: Dr. Kevin C. Zorn, Division of Urology, Department of Surgery, Centre Hospitalier Universitaire de Montréal (CHUM), Montreal, QC, Canada; kevin.zorn@gmail.com 